\title{
ANÁLISE DO MOSAICO SILVÁTICO EM UM FRAGMENTO DE FLORESTA TROPICAL ESTACIONAL NO SUDESTE DO BRASIL ${ }^{1}$
}

\author{
Eliana Cardoso Leite ${ }^{2}$, Ricardo Ribeiro Rodrigues ${ }^{3}$
}

\begin{abstract}
RESUMO - Este estudo foi realizado na "Mata da Câmara", um fragmento de floresta estacional semidecídual localizado em São Roque, SP, e teve como objetivos a identificação e análise do mosaico silvático, discutindose a arquitetura atual da floresta e inferindo sobre sua dinâmica de construção. Utilizou-se o método de inventário de linhas interceptadas, em que se amostraram três áreas de $50 \times 105 \mathrm{~m}$. Os resultados indicaram que as porcentagens de área ocupada por ecounidades em equilíbrio $2 \mathrm{~A}$ foram de 46,8\%, 48,6\% e 75,7\%, respectivamente nas três áreas estudadas. Pode-se concluir que na área $\mathrm{A}$ há uma floresta jovem, na área $\mathrm{B}$ uma floresta em fase de pré-maturidade com sinais de perturbações recentes e antigas e na área $\mathrm{C}$ uma floresta madura com alguns sinais de perturbações antigas. Comparando os resultados desta análise com aqueles obtidos através de levantamento fitossociológico, realizado na mesma área, a análise silvigenética mostrou ser mais uma importante ferramenta para discussão da dinâmica florestal, mas que em alguns caso tende a superestimar o grau de maturidade das florestas. No contexto dos fragmentos florestais remanescentes do Estado de São Paulo, pode-se dizer que a Mata da Câmara representa uma área de floresta relativamente bem preservada.
\end{abstract}

Palavras-chave: Fragmentos florestais, mosaico silvático e São Roque, SP.

\section{SILVATIC MOSAIC ANALYSIS IN A FRAGMENT OF A TROPICAL SEASONAL FOREST IN SOUTHEASTERN BRAZIL}

\begin{abstract}
This study was carried out in "Mata da Câmara", a fragment of a seasonal semideciduous forest, in São Roque - SP, Brazil. The objective of the present work was to identify and analyze the silvatic mosaic, by discussing its current architectural aspects and inferring about its construction dynamics. The line-intercept inventory method was used in three $50 \times 105 \mathrm{~m}$ areas. The results showed that percentages of the area occupied by $2 A$ steady-state eco-units, were $46.8 \%, 48.6 \%$, and $75.7 \%$ for areas $A, B$ and $C$ respectively. It can be concluded that there is a young forest in area A; a pre-mature forest with signs of both recent and old disturbances in area $B$, and in area $C$ a mature forest with signs of old disturbances. Compared with the results of other phytosociological researches carried out in the same area, this analysis showed to be an important tool for the discussion of forest dynamics, though in some cases the mosaic silvatic analysis tended to overestimate the level of forest maturity. It can be stated that among the remaining seasonal forests in the state of São Paulo, "Mata da Câmara" represents a patch of a relatively well-preserved forest.
\end{abstract}

Keywords: Forest fragments, tropical seasonal forest, São Roque and silvatic mosaic.

\footnotetext{
${ }^{1}$ Recebido em 30.10.2007 e aceito para publicação em 19.05.2008.

${ }^{2}$ Departamento de Engenharia Florestal da Universidade Federal de São Carlos (UFSCAR), Sorocaba-SP.E-mail: <cardosoleite@yahoo.com.br>. ${ }^{3}$ Departamento de Ciências Biológicas da ESALQ. E-mail: <rrr@esalq.usp.br>.
} 


\section{INTRODUÇÃO}

Pesquisas em florestas tropicais sempre têm tentado definir o que é uma floresta tropical madura. Existem grande dificuldade e controvérsia nesse sentido devido à enorme heterogeneidade estrutural dessas florestas e à altíssima biodiversidade que abrigam. Essa definição é muito importante, pois constitui a base para o manejo florestal sustentável e para a recuperação de áreas de florestas tropicais degradadas no Brasil e no mundo.

No paradigma ecológico clássico, os ecossistemas são fechados em sua auto-regulação, o processo é determinístico, e espera-se um ponto final estável de sucessão. Nesse caso, os eventos que modulam o ecossistema são considerados "distúrbios" e estes exceção. O paradigma contemporâneo assume que os ecossistemas são abertos, sujeitos a processos externos (inclusive a ação humana) e a distúrbios naturais, sendo múltiplas as possibilidades de trajetórias sucessionais e de pontos de equilíbrio estrutural e florístico.

A sucessão ecológica baseada no monoclímax (CLEMENTS, 1916) segue o modelo clássico, enquanto os trabalhos de Botkin (1990), Pickett et al. (1992) e Parker e Pickett (1999), o modelo contemporâneo.

Muitos autores têm discutido também os mecanismos que asseguram a manutenção da altíssima diversidade presente nas florestas tropicais. Mesmo sem haver consenso entre aqueles que defendem modelos baseados em competição (HECTOR et al., 1999) ou em facilitação (BRUNO et al., 2003), o fato é que essas florestas têm mantido alta diversidade. Alguns autores atribuem a manutenção dessa alta diversidade à ocorrência de perturbações, como na hipótese da perturbação intermediária (CONNEL, 1978). Essa hipótese sustenta que ambientes sujeitos a perturbações de intensidade, freqüência e tamanho intermediários geralmente apresentam maior diversidade do que ambientes nada ou muito perturbados. Assim, o modelo contemporâneo (PARKER e PICKETT, 1999) admite que as perturbações, inclusive as antrópicas, são contingências do ecossistema, indo também de encontro aos conceitos relacionados à Ecologia da Paisagem (HANSSON et al., 1995), que contextualiza o homem como parte integrante do ecossistema. Segundo esse paradigma, os diferentes pontos de equilíbrio possíveis são resultantes de combinações historicamente únicas de processos locais, que podem resultar em composições florísticas distintas no final da sucessão.
Trabalhos que analisam o grau de maturidade de florestas tropicais no Sudeste do Brasil (GANDOLFI etal., 1995; DISLICHetal., 2001;FONSECAeRODRIGUES, 2000; SILVA et al., 2003; SILVA et al., 2004) em geral têm utilizado o método da identificação de espécies e de seus grupos ecológicos (BUDOWSKI, 1970; MARTINEZ-RAMOS, 1985; SWAINE E WHITMORE, 1988; DENSLOW, 1996), em que está implícito o conceito de substituição de espécies como blocos taxonômicos definidos, e a arquitetura arbórea é desconsiderada.

Também se tem utilizado métodos estatísticos (FONSECAeRODRIGUES, 2000; FONSECAeFONSECA, 2004) para análise do mosaico florestal. Whitmore (1975, 1990) foi um dos pioneiros na introdução da idéia de mosaico, dizendo que a floresta é construída por manchas de diferentes idades, ou seja, pelas fases de clareira, construção e maturidade. Outros autores utilizaram termos semelhantes para designar esse processo de construção da floresta, como fases de desenvolvimento (BRUNIG, 1983), partes dinâmicas (PICKET e THOMPSON, 1978) e padrão de fases espaço-temporais (DOYLE, 1981).

A fragmentação de florestas estacionais é um processo histórico no Sudeste do Brasil, especialmente no interior do Estado de São Paulo, devido à expansão agrícola e urbana. De um total de $80 \%$ do território do Estado coberto por formações nativas, hoje se têm menos de $13 \%$ dessas formações como remanescentes (KRONKA et al., 2003).

Devido a esse acelerado processo de desmatamento, por anos a fio a comunidade científica tem trabalhado com a expectativa de que, ao longo do tempo, somente as florestas dentro de Unidades de Conservação seriam mantidas (VICTOR, 1975) no Estado de São Paulo. No entanto, com os trabalhos realizados por Kronka et al. (1993), Kronka et al. (2003) tem se constatado relativo aumento de área ocupada por fragmentos de floresta estacional, o que se espera também refletir em um aumento na diversidade de espécies. Outros pesquisadores (CARDOSO-LEITE, 1995; KOTCHETKOFF-HENRIQUES et al., 2005) mostraram que fragmentos florestais pequenos podem ter alta diversidade de espécies, indicando que, muitas vezes, o histórico de perturbações pode influenciar até mais que o próprio tamanho do fragmento.

Este trabalho assume o modelo contemporâneo (PICKETT et al., 1992; PARKER e PICKETT, 1999) e os conceitos da Ecologia da Paisagem (HANSSON et al., 1995) que contextualizam o homem como parte 
do ecossistema. Dessa forma, além de se aceitar esse paradigma contemporâneo, faz-se necessário e útil testar novos métodos de análise da construção da floresta. Este estudo utiliza um método de análise que, embora pouco difundido no meio acadêmico no Brasil, pode mostrar-se bastante eficaz. Denominado silvigênese, ou análise do mosaico silvático (OLDEMAN, 1983), o método baseia-se na arquitetura arbórea e nas suas transformações em função das trocas energéticas que ocorrem no estrato vertical da floresta (HALLÉ et al., 1978; OLDEMAN, 1978).

Alguns autores (WILLS et al., 2006), ao estudarem a manutenção da diversidade em florestas tropicais, encontraram dificuldades em separar árvores jovens de árvores maduras, enquanto outros (FONSECA e RODRIGUES, 2000) se depararam com empecilhos em separar estatisticamente árvores maduras (sadias) de árvores velhas (com copa danificada e tronco atacado por pragas), também denominadas "árvores do presente e árvores do passado" (TORQUEBIAU, 1986). Nesses casos, a análise da arquitetura arbórea poderia ter contribuído bastante.

A silvigênese (OLDEMAN, 1983) pressupõe a existência de uma superfície de inversão ecológica, ou nível de inversão na floresta, em que a energia se transforma dentro do estrato florestal e na qual podem ocorrer ramificações laterais (reiteração) dos indivíduos arbóreos. Segundo esse autor, essa superfície de inversão ecológica deve situar-se na metade da altura máxima das árvores do dossel. Baseando-se em características morfológicas, Oldeman (1983) sugeriu um método relativamente simples para categorização das árvores: árvores do presente, do passado e do futuro, considerando árvores do presente aquelas saudáveis com ramificação lateral, árvores do passado aquelas mortas em pé ou com sinais visíveis de degradação e árvores do futuro aquelas jovens com pouca ou nenhuma reiteração, ou seja, pouco ramificadas, como proposto também por Torquebiau (1986). Essas árvores, reunidas em grupos junto com as áreas de clareiras, constituiriam "ecounidades" (reorganização, desenvolvimento, equilíbrio e degradação) que resultariam no mosaico florestal denominado "silvático". Estudos recentes têm apontado que a quantidade de energia que entra na floresta altera-se em diferentes alturas do estrato florestal (MONTGOMERY e CHAZDON, 2001).

O mosaico silvático (OLDEMAN, 1983), também utilizado por outros autores em estudos desta natureza (TORQUEBIAU, 1986) em florestas tropicais, assemelha- se ao mosaico sucessional de Whitmore (1975, 1990), em que as fases de clareira, construção e maturidade são representadas pelas ecounidades em reorganização, desenvolvimento e equilíbrio, porém o enfoque básico é diferente, pois no primeiro é considerada essencialmente a arquitetura da comunidade arbórea. Assim, a análise do mosaico silvático, no contexto do modelo ecológico contemporâneo (PARKER e PICKETT, 1999), parece bastante apropriada. Além disso, o uso de critérios arquiteturais para discussão da dinâmica da floresta pode mostrar-se bastante útil.

O objetivo deste trabalho foi analisar o grau de maturidade de um fragmento florestal no Sudeste do Brasil, com a utilização da silvigênese.

\section{MATERIAL E MÉTODOS}

O local de estudo foi o fragmento florestal denominado "Mata da Câmara" (2331'26 S, 4706'45 W), localizado na Estância Turística de São Roque (Figura 1), com 128 ha. São Roque dista $50 \mathrm{~km}$ da cidade de São Paulo, no Sudeste do Brasil. Há cerca de 100 anos a área vem sendo conservada, e em 1999 transformouse em Parque Natural Municipal de São Roque (Lei Municipal 2.499, de 19/03/1999).

Oclima da regiãoé Cfb (SETZER, 1966). A vegetação foi classificada (RIZZINI, 1979; BRASIL, 1992) como Floresta Estacional Semidecidual. Geologicamente, a região pertence ao Grupo São Roque (ALMEIDA et al., 1981). O relevo foi identificado como montanhoso (PONÇANO et al., 1981), e o solo predominante como Pdzólico (PRADO, 1995) ou Argissolo (EMBRAPA, 1999). Na área, as altitudes variam de 850 a $1.025 \mathrm{~m}$.

O estudo do mosaico silvático (OLDEMAN, 1983) foi realizado por meio do método de inventário de linhas interceptadas por árvores do dossel (TORQUEBIAU, 1986). Cada uma das três áreas utilizadas para o levantamento fitossociológico(CARDOSO-LEITE, 1995) foi ampliada em $20 \mathrm{~m}$ na largura. Amostraram-se três áreas de $50 \mathrm{~m} \times 105 \mathrm{~m}$ cada, onde foram dispostas 10 linhas paralelas entre si, no sentido do comprimento, e distantes $5 \mathrm{~m}$ uma da outra. Foram analisadas, então, três áreas de 0,525 ha cada (Figura 1).

Foram amostrados todos os indivíduos arbóreos dominantes, cujas projeções horizontais das copas interceptavam as linhas, considerando-se como árvore dominante aquela cuja copa representava a cobertura mais alta no ponto amostrado, ou seja, não havia nada

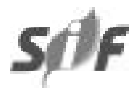

R. Árvore, Viçosa-MG, v.32, n.3, p.443-452, 2008 
cobrindo-a. Foram tomadas medidas de distâncias do tronco e da projeção da copa desses indivíduos até a linha, num sistema de eixos ortogonais (coordenadas x e y), além da altura total (Ht) e da altura do fuste (Hf), que foram medidas com o uso de um podão de $12 \mathrm{~m}$ de altura. Esses indivíduos foram classificados, no campo, quanto à sua arquitetura em árvores do futuro, árvores do presente e árvores do passado, utilizando-se para tal os critérios propostos por Torquebiau (1986). Essa metodologia foi anteriormente utilizada por outros autores no Brasil (ENGEL e PRADO, 1992; OLIVEIRA, 1997).

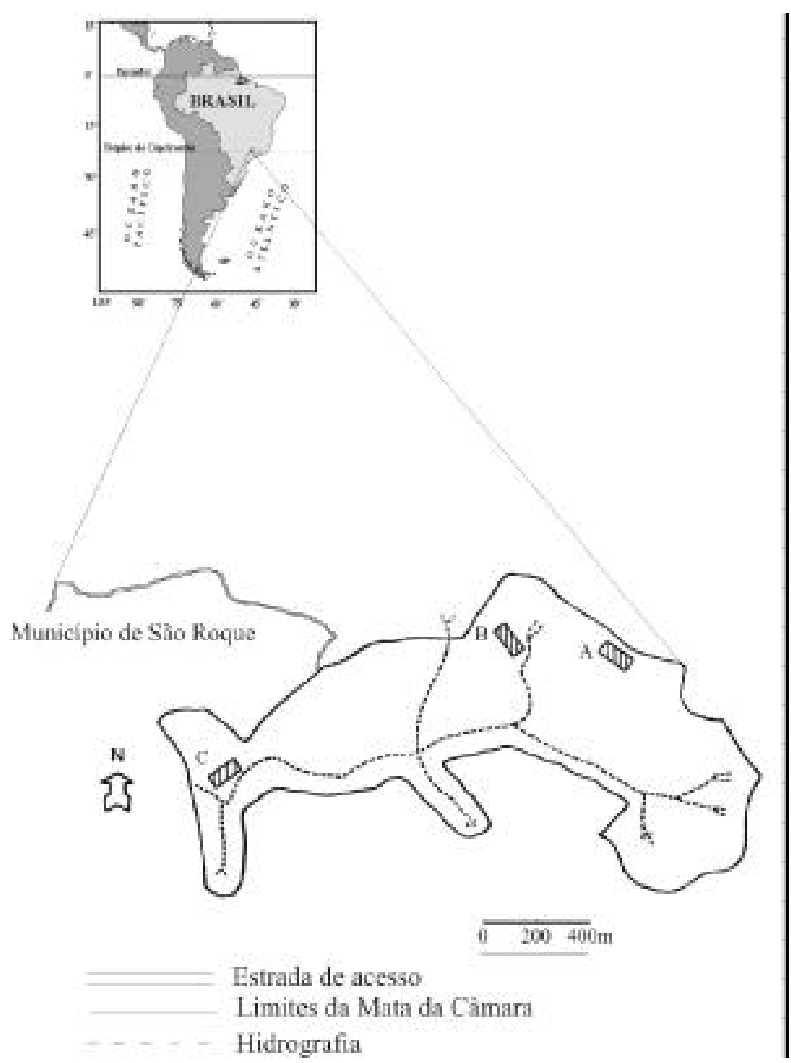

Figura 1 - A área de estudo - Mata da Câmara, São Roque, $\mathrm{SP}$, e sua localização no Brasil e na América do Sul. A, B e C representam as áreas amostradas.

Figure 1 - The study area-Mata da Câmara, São Roque, $S P$, and its location in Brazil and Latin America. $A, B$, and $C$ indicate the study areas.

Para o mapeamento dos indivíduos e das ecounidades, utilizou-se o programa Autocad. e para os cálculos da área ocupada por cada ecounidade, o programa Idrisi. As ecounidades foram estabelecidas a partir da união das copas de árvores da mesma categoria. Também foram definidas como: Ecounidades em reorganização - para clareiras; Ecounidades em desenvolvimento - para árvores do futuro; Ecounidades em degradação - para árvores do passado; e Ecounidades em equilíbrio dinâmico - para árvores do presente. Para Torquebiau (1986), árvores do presente são aquelas adultas, sadias; árvores do passado são as mortas em pé, ou com sinais de degradação; e árvores do futuro são as jovens, com altura baixa e copa pouco ramificada na lateral.

As árvores do presente foram subdivididas em quatro categorias, a saber: $1 \mathrm{~A}$ - árvores baixas com ramificação alta, 1B - árvores baixas com ramificação baixa, 2A - árvores altas com ramificação alta e 2B árvores altas com ramificação baixa. Nessa classificação, considerou-se árvore baixa aquela cuja altura total era menor que a metade da altura do dossel da floresta, árvore alta aquela cuja altura total era maior que a metade da altura do dossel da floresta, como ramificação baixa aquela que ocorria abaixo da metade da altura do indivíduo arbóreo e como ramificação alta aquela que ocorria acima da metade da altura do indivíduo arbóreo. Para maiores detalhes sobre o método, recomenda-se consultar os trabalhos de Torquebiau (1986) e Engel e Prado (1992). Parte-se do pressuposto de que árvores que tiveram seu desenvolvimento inicial em condições de dossel fechado (sombra) em geral crescem em altura e ramificam somente depois de atingir a superfície de inversão ecológica, ou seja, a metade superior do estrato florestal. E aquelas que se desenvolveram inicialmente em condições de maior quantidade de energia, ou seja, de abertura do dossel, apresentam crescimento interrompido e ramificações (fuste) em alturas mais baixas.

\section{RESULTADOS E DISCUSSÃO}

A altura máxima do dossel foi de $25 \mathrm{~m}$, portanto a superfície de inversão morfológica (OLDEMAN, 1983) foi considerada como ocorrendo na altura de $12,5 \mathrm{~m}$, seguindo a metodologia utilizada (TORQUEBIAU, 1986).

$\mathrm{Na}$ área A foram amostrados 221 indivíduos arbóreos, sendo 48 árvores do futuro, 152 árvores do presente e 21 árvores do passado (incluindo duas árvores mortas em pé). Na área $\mathrm{B}$ foram amostrados 188 indivíduos, sendo 26 árvores do futuro, 155 do presente e sete do passado (incluindo duas árvores mortas em pé). $\mathrm{Na}$ área $\mathrm{C}$ foram amostrados 188 indivíduos, sendo 27 árvores do futuro, 153 árvores do presente e oito árvores do passado. 
A Figura 2 apresenta o mosaico florestal nas áreas A, B e C. Na Tabela 1, apresenta-se a porcentagem de área ocupada por cada uma das ecounidades.
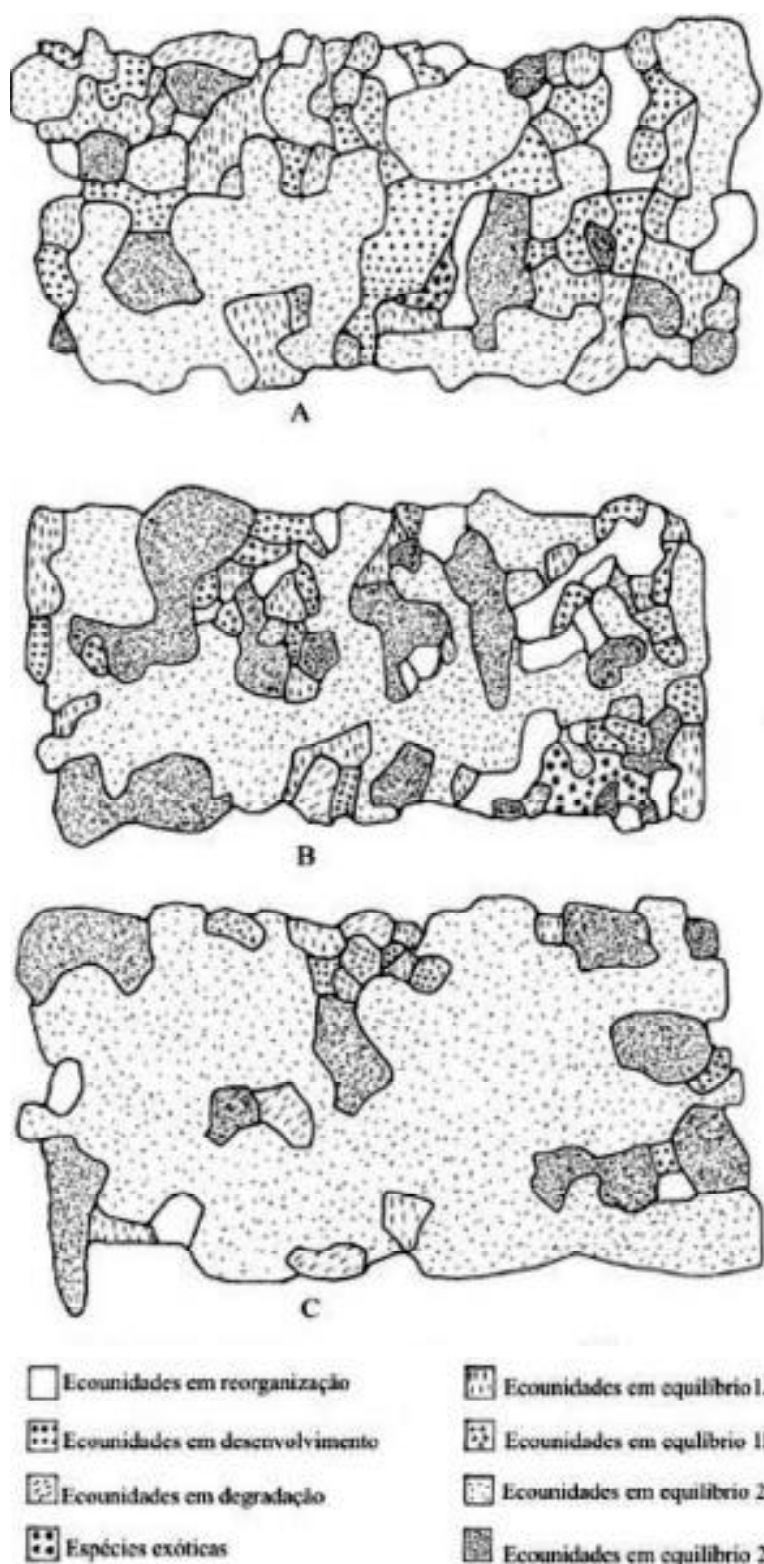

$\begin{array}{lll}0 & 10 & 20 \mathrm{~m}\end{array}$

Figura 2. A - Mosaico silvático na área A; B - Mosaico silvático na área B; C - Mosaico silvático na área C. Mata da Câmara, São Roque, SP, Brasil.

Figure 2. A - Silvatic mosaic in area A; Silvatic mosaic in area B; Silvatic mosaic in area C. Mata da Câmara, São Roque, SP, Brazil.
$\mathrm{Na}$ área $\mathrm{A}$, observa-se que, mesmo com a grande porcentagem de área ocupada por ecounidades $2 \mathrm{~A}$ (Tabela 1), não se pode visualizar a existência de uma matriz (Figura 2) ou como denominou Torquebiau (1986), uma "rede" constituída predominantemente por um tipo de ecounidade, em que as demais estariam inseridas. Mesmo assim, as ecounidades em equilíbrio $2 \mathrm{~A}$ não chegaram a ocupar $50 \%$ da área; enquanto Torquebiau (idem), uma "rede" onde as demais ecounidades estariam inseridas. As ecounidades em equilíbrio $2 \mathrm{~A}$ não chegaram a ocupar $50 \%$ da área. Torquebiau (idem) afirmou que as ecounidades $2 \mathrm{~A}$ devem corresponder à fase de maturidade da floresta, descrita por outros autores (WHITMORE, 1990) como a fase em que a floresta apresenta árvores altas e possui vários estratos bem definidos. Nessa área, a porcentagem de área ocupada por ecounidades em desenvolvimento foi relativamente grande $(14,5 \%)$, assim como por ecounidades em degradação $(5,7 \%)$, quando comparadas com as áreas B e C (Tabela 1). Esses resultados indicaram perturbações recentes na área onde, provocando a abertura do dossel, se expuseram os indivíduos jovens, ou seja, as árvores do futuro. A porcentagem de área, também relativamente grande, ocupada por ecounidades em equilíbrio $1 \mathrm{~A}$ $(13,8 \%)$ indicou perturbações recentes no dossel que devem ter exposto árvores do estrato intermediário (subdossel ou sub-bosque) da floresta, que devem ter se desenvolvido à sombra e, portanto, naturalmente ramificadas, ou árvores dos estratos superiores (dossel) que, inicialmente, se desenvolveram à sombra e após a perturbação sofreram reiteração. Observando que nessa área as porcentagens de ecounidades em reorganização e degradação (representadas pelas clareiras e pelas árvores mortas ou morrendo) foram altas em comparação com as outras áreas, pode-se dizer que a área se encontrava mais degradada, ou seja, havia sinais de que tenha sofrido perturbações mais freqüentemente.

$\mathrm{Na}$ área $\mathrm{B}$, notou-se grande porcentagem de área ocupada pelo conjunto de ecounidades em equilíbrio dinâmico 2A e 2B (Tabela 1), que em conjunto formavam uma matriz onde as demais estavam inseridas (Figura 2). No entanto, as ecounidades $2 \mathrm{~A}$, consideradas como indicadoras da fase de maturidade da floresta (TORQUEBIAU, 1986), também não chegaram a 50\% da área, como na área A. A área ocupada por ecounidades 2B (Tabela 1) representava indivíduos que cresceram inicialmente em condições de floresta mais ou menos 
aberta, pois ramificaram cedo, embora com o passar do tempo tenham atingido o dossel superior. Isso reflete sinais de perturbações antigas nessa área. As ecounidades em reorganização, que representam as clareiras, ocuparam 8,3\% da área total, com valor próximo ao encontrado na área $\mathrm{A}$ e maior que da área $\mathrm{C}$. $\mathrm{Na}$ área $\mathrm{C}$ (Figura 2), as ecounidades em equilíbrio $2 \mathrm{~A}$ ocuparam 75,7\% da área total (Tabela 1), formando uma matriz onde as demais ecounidades se apresentaram inseridas. Na ordem de ocupação dessa área, seguiramse as ecounidades em equilíbrio $2 \mathrm{~B}$, sinalizando também perturbações antigas na área, embora em menor proporção do que apresentado na área B.

Por meio dos resultados apresentados para o mosaico silvático (Figura 2 e Tabela 1), pode-se dizer que a área A é a área mais jovem, com indícios de perturbação recente; a área $\mathrm{B}$ apresenta condição intermediária, com indícios de perturbações antigas e recentes; e a área $\mathrm{C}$, a área mais madura, com poucos indícios de perturbação antiga. Infelizmente, não se tem o registro do histórico de perturbações da área de estudo, com datas precisas e origem dos impactos sofridos, pois esses dados poderiam ser checados com os resultados obtidos, de modo a testar a eficiência do método utilizado.

Comparando os resultados com os poucos estudos desta natureza realizados no Brasil (Tabela 2), podese observar que os resultados aqui apresentados são muito similares aqueles registrados em Linhares-ES (ENGEL e PRADO, 1992), apesar de tratarem de formações diferentes, respectivamente floresta estacional e ombrófila, com tamanhos de área bastante distintos (Tabela 2). Os resultados de São Roque e Linhares são também bastante similares aos registrados por Torquebiau (1986) em uma floresta de Dipterocarpáceas na Indonésia, mesmo com as restrições da comparação, por se tratar de formações muito distintas. Em todos esses estudos predominou, em porcentagem de área, a ecounidade $2 \mathrm{~A}$, considerada como indicadora de floresta madura (TORQUEBIAU, 1986).

Em Piracicaba-SP(OLIVEIRA, 1997), foi registrada grande proporção de área ocupada por clareiras, por ecounidades em equilíbrio $1 \mathrm{~A}$ e $2 \mathrm{~B}$, diferindo bastante dos resultados aqui registrados para São Roque. Isso pode ser explicado pela recente incidência de fogo e de exploração seletiva de madeira que ocorreram na área (OLIVEIRA, 1997). Essa autora conclui tratar-se de um fragmento florestal instável.

Outros estudos em andamento também no interior do Estado de São Paulo (BOTREL et al., 2003) apontaram inicialmente grande proporção de ecounidades em degradação.

Analisando o tamanho e grau de proteção das áreas utilizadas para comparação (Tabela 2), podese dizer que há indícios de que a proteção influenciou mais o grau de conservação dessas áreas que o próprio tamanho dos fragmentos. Observando as áreas de São Roque e Linhares (Tabela 2), pode-se verificar que ambas representam trechos de floresta madura ou em fase de pré-maturidade, e onde estudos prévios (CARDOSOLEITE, 1995; JESUS e ROLIM, 2005) registraram índices de diversidade acima da média para ambas. Essas duas áreas, a despeito de seu tamanho bastante distinto, foram ao longo dos anos mais intensamente protegidas que a área de Piracicaba (Tabela 2), pois em São Roque se tem um Parque Municipal e em Linhares, uma Reserva Particular. No entanto, essa discussão não é conclusiva, pois seriam necessários estudos mais aprofundados para sustentar tais afirmações.

Quando comparados os resultados aqui obtidos com aqueles registrados no levantamento fitossociológico (Tabelas 1 e 3) e com a identificação dos grupos ecológicos das espécies (CARDOSO-LEITE 1995), pode-se dizer que as três áreas não diferem muito, em porcentagem de indivíduos, de grupos ecológicos iniciais e tardios.

Tabela 1 - Proporção das diferentes ecounidades nas áreas A, B e C (em porcentagem), em relação à área total, Mata da Câmara, São Roque, SP, Brasil

Table 1 - Proportions of the different ecounits in areas A, B, and C (in percentage), in relation to the total area, Mata da Câmara, São Roque, SP, Brazil

\begin{tabular}{lcccccccc}
\hline & Reorg. & Desen. & 1A & 1B & 2A & 2B & Degrad. & Espécies Exóticas \\
\hline Área A & 6,4 & 14,5 & 13,8 & 2,8 & 46,8 & 9,3 & 5,7 & 0,7 \\
Área B & 8,3 & 3,9 & 7,7 & 4,4 & 48,6 & 22,2 & 2,5 & 2,4 \\
Área C & 1,2 & 0,7 & 2,2 & 1,5 & 75,7 & 16,5 & 2,2 & 0,0 \\
Média & 5,3 & 6,4 & 7,9 & 2,9 & 57,0 & 16,0 & 3,5 & 1,0 \\
\hline
\end{tabular}

R. Árvore, Viçosa-MG, v.32, n.3, p.443-452, 2008 
Tabela 2 - Comparação das porcentagens de área ocupadas pelos diferentes tipos de ecounidades, deste trabalho, com outros estudos realizados em florestas tropicais brasileiras. Mata da Câmara, São Roque, SP, Brasil

Table 2 - Comparison of percentages of the area occupied by the different types of ecounits of this study with other studies of the Brazilian tropical forest. Mata da Câmara, São Roque, SP, Brazil

\begin{tabular}{|c|c|c|c|c|c|c|c|c|c|}
\hline & $\begin{array}{c}\text { Tamanho/ Categoria } \\
\text { de Proteção }\end{array}$ & Reorg. & Desenv & $1 \mathrm{~A}$ & 1B & $2 \mathrm{~A}$ & $2 \mathrm{~B}$ & Degrad & $\begin{array}{c}\text { Maturidade/ Estabilidade - } \\
\text { dados dos autores }\end{array}$ \\
\hline $\begin{array}{l}\text { São Roque- } \\
\text { FES * }\end{array}$ & $\begin{array}{l}127,89 \text { ha } \\
\text { Parque Municipal }\end{array}$ & 5,3 & 6,4 & 7,9 & 2,9 & 57,0 & 16,0 & 3,5 & $\begin{array}{l}\text { Floresta madura ou } \\
\text { pré-madura }\end{array}$ \\
\hline $\begin{array}{l}\text { Piracicaba - } \\
\text { FES** }\end{array}$ & 4,9 ha & 10,9 & 10,8 & 20,3 & 6,6 & 27,4 & 18,8 & 5,1 & Floresta instável ou jovem \\
\hline $\begin{array}{l}\text { Linhares } \\
\text { FOD } * * *\end{array}$ & $\begin{array}{l}21.787 \text { ha } \\
\text { Reserva Particular }\end{array}$ & 3,2 & 9,4 & 5,5 & 11,7 & 42,4 & 23,4 & 4,3 & Floresta madura \\
\hline
\end{tabular}

* This study, ** Oliveira (1997), *** Engel e Prado (1992).

Fonte: * Este estudo, ** OLIVEIRA, 1997; *** ENGEL; PRADO, 1992.

Tabela 3 - Comparação entre as porcentagens de indivíduos de diferentes padrões arquiteturais com as porcentagens de indivíduos de espécies dos diferentes grupos ecológicos (CARDOSO-LEITE, 1995). P = espécies pioneiras, $\mathrm{SI}=$ espécies secundárias iniciais, $\mathrm{ST}=$ espécies secundárias tardias, $\mathrm{SC}=$ espécies sem caracterização. Mata da Câmara, São Roque, SP, Brasil

Table 3 - Percentage of individuals of different architectural patterns in comparison with the percentage of individuals of species of different ecological groups (CARDOSO-LEITE, 1995). P= pionner species, $S I=$ secondary early species, $S T=$ secondary latter species, $S C=$ species without characterization. Mata da Câmara, São Roque, SP, Brazil

\begin{tabular}{lccccccc}
\hline & Futuro & Presente & Passado & P & SI & ST & SC \\
\hline Área A & 21,7 & 68,8 & 9,5 & 22 & 43 & 32 & 3 \\
Área B & 13,8 & 82,4 & 3,6 & 32 & 28 & 38 & 2 \\
Área C & 14,3 & 81,4 & 4,3 & 13 & 46 & 39 & 2 \\
\hline
\end{tabular}

A área B obteve maior porcentagem de indivíduos de espécies pioneiras, seguidas das áreas A e C. Em relação às espécies secundárias inicias, as áreas $\mathrm{A}$ e $\mathrm{C}$ registraram resultados próximos; e em relação às espécies tardias, as áreas B e C apresentaram resultados também próximos. Assim, pelos dados da Tabela 3, obtidos pela identificação das espécies e respectivos grupos ecológicos (CARDOSO-LEITE, 1995), as três áreas são bastante similares, no entanto, quando se soma a porcentagem de indivíduos de espécies iniciais $(\mathrm{P}+\mathrm{SI})$ e compara-se com a porcentagem de indivíduos de espécies tardias (ST), observa-se uma suave diminuição nos grupos iniciais de A, para B e para $\mathrm{C}$, bem como um suave aumento no grupo tardio, também no mesmo sentido, o que sinaliza que a área A deve ser a mais jovem das três, as áreas B e C apresentam condição de maturidade um pouco mais avançada. Porém, em nenhuma delas a porcentagem de indivíduos de espécies tardias foi maior que $50 \% \%$, o que alguns autores consideram como critério para definir a maturidade da floresta (DISLICH et. al., 2001). A Tabela
3 mostra também que a porcentagem de árvores do presente, do passado e do futuro foi muito similar entre as áreas $\mathrm{B}$ e $\mathrm{C}$, sendo que a área $\mathrm{A}$ registrou menor porcentagem de árvores do presente e maior porcentagem de outros grupos (passado e futuro), o que indica presença de perturbações nessa área.

Houve, assim, diferença nos resultados da análise do grau de maturidade da Mata da Câmara, com a utilização da fitossociologia (porcentagem de indivíduos de grupos ecológicos distintos) e silvigênese, em que a segunda, em alguns casos, parece indicar um grau mais adiantado de maturidade, a exemplo do que ocorreu na área C. No entanto, os dados da fitossociologia (CARDOSO-LEITE, 1995) utilizados para comparação (Tabela 3) foram bastante pontuais, não permitindo maiores inferências.

Nesse sentido, Machado (2005), estudando os processos de regeneração em um fragmento florestal em Minas Gerais, propôe um modelo hipotético para analisar as mudanças ocorridas ao longo de cinco anos 
no fragmento estudado, num contexto silvigenético. Propôs também que deve ser considerada como estável ou madura a fase em que a área basal e a densidade de indivíduos permaneçam mais ou menos inalterados (que corresponderia às ecounidades em equilíbrio); fase de degradação aquela em que a área basal e densidade de indivíduos diminuem; fase de construção inicial, aquela em que tanto área basal quanto a densidade aumentam; e fase de construção tardia, ou autodesbaste, aquela onde a área basal aumenta e a densidade de indivíduos diminui. Dessa forma, mesmo sem ter utilizado a análise silvigenética (TORQUEBIAU, 1986) baseada na arquitetura arbórea, o modelo proposto por Machado (2005) facilitaria a comparação de resultados de silvigênese com resultados de análise de métodos quantitativos, como a fitossociologia. No entanto, para se aplicar esse modelo hipotético seriam necessárias análises quantitativas repetidas ao longo do tempo, para acompanhar a evolução da área basal e da densidade de indivíduos, o que, sem dúvida, dificultaria sua aplicação devido ao aumento de tempo e custos das análises.

Vale ressaltar que neste trabalho o mapeamento das ecounidades foi muito facilitado pelo conhecimento prévio das espécies amostradas. Em muitos indivíduos, esse conhecimento prévio ajudou a distinção entre árvores do futuro e árvores do presente pouco reiteradas. Como afirmou Torquebiau (1986), algumas espécies nunca apresentam reiteração adaptativa (ramificação), como é o caso das espécies da famíliaArecaceae, algumas espécies das famílias Annonaceae e Myristicaceae, além de algumas espécies pioneiras. Assim, a grande vantagem da silvigênese, discutida por vários autores (OLDEMAN, 1983; ENGEL, 1993) como a independência do conhecimento taxonômico, fica um pouco comprometida, ou seja, apesar ser útil e prático, a análise silvigenética também possui falhas e limitações

Uma das principais restrições do levantamento fitossociológico é o fato de este método constituirse numa análise pontual do ecossistema em questão, não permitindo fazer inferências com segurança sobre eventos ocorridos antes da coleta de dados ou prever aqueles que porventura venham a ocorrer. Nesse sentido, alguma possibilidade de entendimento de eventos passados e de previsão do potencial de regeneração do ecossistema, proporcionada pela silvigênese, pode enriquecer muito os resultados obtidos por métodos mais frequentemente utilizados, como a fitossociologia e identificação dos grupos ecológicos das espécies.
Pode-se dizer, portanto, que os dois métodos são eficientes na análise do grau de maturidade de florestas tropicais, mas que ambos apresentam falhas e limitações. Assim, a silvigênese mostrou ser mais um importante instrumento na análise do mosaico florestal, mas que deve ser associado a métodos mais tradicionalmente utilizados, como a fitossociologia.

\section{CONCLUSÕES}

$\mathrm{O}$ trecho de mata da área $\mathrm{C}$ representa uma floresta madura com alguns sinais de perturbações antigas, enquanto na área B se tem uma floresta em fase de pré-maturidade com sinais de perturbações recentes e antigas, e na área A há uma floresta jovem ou imatura, mas com grande potencial de regeneração futura.

Com base nos resultados deste estudo e tendo como referencial as Florestas Estacionais Semidecíduas do Estado de São Paulo e, ainda, admitindo a possibilidade de diversos pontos de equilíbrio estrutural e florístico no processo de desenvolvimento da floresta, conclui-se que grande parte do fragmento florestal da Mata da Câmara/São Roque/SP está bem conservada, a despeito de seu reduzido tamanho.

\section{AGRADECIMENTOS}

À Prefeitura Municipal de São Roque e ao pesquisador Issao Ishimura, do Instituto Agronômico de Campinas - Estação Experimental de São Roque, pelo apoio logístico no desenvolvimento do trabalho, ao senhor Arnaldo Oliveira, pelo auxílio nos trabalhos de campo; e à Profa. Dra. Vera Lex Engel - da UNESP - Botucatu, pelo encorajamento e auxílio na metodologia.

\section{REFERÊNCIAS}

ALMEIDA, F. F. M. et al. Mapa geológico do estado de São Paulo. São Paulo: IPT, 1981. (Série Monografias, 6)

BOTREL, R. T.; RODRIGUES, R. R.; YAMAMOTO, K. Caracterização mosaico silvigênica de um trecho de Floresta Estacional Semidecidual localizado na Estação Ecológica de Caetetus. In: CONGRESSO DE ECOLOGIA DO BRASIL, 6., 2003, Fortaleza. Anais... Fortaleza: Universidade Federal do Ceará, 2003. p.472-473. 
BRASIL. Fundação Instituto Brasileiro de Geografia e Estatística - IBGE. Secretaria do Orçamento e Coordenação da Presidência da República. Manual Técnico da Vegetação Brasileira. Rio de Janeiro: 1992. (Série Manuais Técnicos em Geociências).

BRUNIG, E. F. Vegetation structure and growth. In: GOLLEY, F.B. (Ed.). Ecosystem of the world, 14A. Tropical rain forest ecosystems. Amsterdam: Elsevier, 1983. p.49-75.

BRUNO, J. F.; STACHOWICZ, J. J.; BERTNESS, M. D. Inclusion of facilitation into ecological theory. Trends in Ecology an Evolution, v.18, n.3, p.119-125, 2003.

BUDOWSKI, G. The distinction between old secondary and climax species in tropical central american lowland forests. Tropical Ecology, v.11, n.1, p.44-48, 1970.

CARDOSO-LEITE, E. Ecologia de um fragmento florestal em São Roque, SP: florística, fitossociologia e silvigênese. 1995. FOLHAS. Dissertação (Mestrado) - Universidade Estadual de Campinas, Campinas, 1995.

CARDOSO-LEITE, E.; RODRIGUES, R.R. Fitossociologia e caracterização sucessional de um fragmento de floresta estacional no sudeste do Brasil. Revista Árvore. Submetido.

Clementes, F. E. Plant Sucession. Washington: Carnegie Inst. Washington Publisher, 1916.

CONNEL, J. H. Diversity in tropical rain forests and coral reefs. Science, v.199, n.24, p.1302-1310, 1978.

DENSOW, J. S. Functional group diversity and responses to disturbance. In: ORIANS, G.H.; DIRZO, R.; CUSHMAN, J. H. (Eds).

Biodiversity an ecosystem process in tropical forests. Berlin: Springer-Verlarg, 1996. p.127-151. (Ecological Studies, 122)

DISLICH, R.; CERSÓSIMO, L.; MANTOVANI, W. Análise da estrutura de fragmentos florestais no Planalto Paulistano-SP. Revista Brasileira de Botânica, v.24, n.3, p.321-332, 2001.
DOYLE, T. W. The role disturbance in the gap dynamics of a montane rain forest: an application of a tropical forest succesion model. In: WEST, D. C; SHUGART, H. H. \& BOKIN, D. B. (Eds.) Forest sucession: concept and application. New York: Springer Verlag, 1981.

EMPRESA BRASILEIRA DE PESQUISA AGROPECUÁRIA - EMBRAPA. Centro Nacional de Pesquisa de Solos. Sistema brasileiro de classificação de solos. Brasília: Embrapa Produção de Informações; Rio de Janeiro: Embrapa Solos, 1999. 412p.

ENGEL, V. L. \& PRADO, P. I. K. L. Aspectos da silvigênese de uma mata pluvial Atlântica em Linhares, ES. In: CONGRESSO NACIONAL DE ESSÊNCIAS NATIVAS, 2., 1992, LOCAL.Anais... LOCAL: 1992. p.163-168.

ENGEL, V. L. Silvigênese, dinâmica de fragmentos e a conservação de florestas tropicais. Botucatu: Universidade Estadual de São Paulo, 1993. (Série Florestal FEPAF, v. 1, n.1)

FONSECA, R. C. B.; RODRIGUES, R. R. Análise estrutural e aspectos do mosaico sucessional de uma floresta semidecídua em Botucatu, SP.

Scientia Florestalis, v.57, p.27-43, 2000.

FONSECA, R. C. B., FONSECA, I. C. B.Utilização de métodos estatísticos multivariados na caracterização do mosaico sucessional em floresa semidecidual. Revista Árvore, v.28, n.3, p.351-359, 2004.

GANDOLFI, S.; LEITÃO-FILHO, H. F; BEZERRA, C. L. Levantamento florístico e caráter sucessional das espécies arbustivo-arbóreas de uma floresta mesófila semidecídua no município de Guarulhos, SP. Revista Brasileira de Biologia, v.55, n.4, p.753-767, 1995.

HANSSON, L.; FAHRIG, L.; MERRIAN, G. (Eds. ) Mosaic landscape and ecological processes. IALE Studies in landscape ecology II. London: Chapman and Hall, 1995.

HARTSHORN, G. S. Neotropical forest dynamics. Biotropica (Special supplement of Tropical Sucession), v. 12, p.23-30, 1980. 
HECTOR, A. et al. Plant diversity and productivity experiments in european grasslands. Science, v.286, n.5442, p.1123-1127, 1999.

JESUS, R. M \& ROLIM, S. G. Fitossociologia da Mata Atlântica de Tabuleiro . Viçosa, MG: Sociedade de Investigação Florestal, 2005. 149p. (Boletim Técnico SIF, 19).

KRONKA, J. N. F. et al. Inventário florestal do Estado de São Paulo. São Paulo: Instituto Florestal, 1993. 200p.

KRONKA, F. J. N. et al. Levantamento da vegetação natural e caracterização de uso do solo no Estado de São Paulo. In: SIMPÓSIO BRASILEIRO DE SENSORIAMENTO REMOTO, 11., 2003, Belo Horizonte. Anais.. Belo Horizonte: INPE, 2003. p.2779-2785.

MARTINEZ-RAMOS, M. Claros, ciclos vitales de los arbores tropicales y regeneración natural de las selvas altas perenifolias. In: GOMEZ-POMPA, A.; DEL AMO, R., S. (Eds.) Investigaciones sobre la regeneración de selvas altas en Veracruz, México. México: CECSA, INIREB, 1985. p.191-239.

MONTGOMERY, R. A.; CHAZDON, R. L. Forest structure, canopy architecture, and light transmitance in tropical wet forests. Ecology, v.82, n.10, p.2707-2718, 2001.

HALLÉ, F.; OLDEMAN, R. A. A.; TOMLINSON, P. B. Tropical trees and forests. Berlin, Springer-Verlag, 1978. 441p.

OLDEMAN, R. A. A. Architecture an energy exchange of dicotyledonous trees in the forest. In: TOMLINSON, P. B. \& ZIMMERMANN, M. H. (Eds.) Tropical trees as living systems. Cambridge, University Press Cambridge, 1978.

OLDEMAN, R. A. A. Tropical rain forest, architecture, silvigenesis and diversity. In: SUTTON, S.L; WHITMORE, T.C; CHADWICK, A.C. (Eds.). Tropical rain forest ecology an management. Oxford, Black Scientific Oxford, 1983. p.139-150.

OLIVEIRA, R. E. Aspectos da dinâmica de um fragmento florestal em PiracicabaSP:silvigênese e ciclagem de nutrientes. 1997. Dissertação (Mestrado) Escola Superior de Agricultura Luiz de Queiroz, Piracicaba, 1997.

R. Árvore, Viçosa-MG, v.32, n.3, p.443-452, 2008
PARKER, V. T.; PICKETT, S. T. A. Restoration as an ecosystem process: Implications of modern ecological paradigm. In: URBASKA, K.M.; WEBB, N.R.; EDWARDS, P.J. Restoration ecology and sustainable development. Cambridge: Cambridge University Press, 1999. p.17-32.

PRADO, H. Manual de classificação de solos do Brasil. Jaboticabal: Unesp/Funep, 1995.

PICKETT, S. T. A \& THOMPSON, J. N. Patch dynamics and the design of nature reserves. Biological Conservation, v.13, n.1, p.27-37, 1978.

PONÇANO, W. L. et al. Mapa geomorfológico do Estado de São Paulo. São Paulo: IPT, 1981. (IPT- Série Monografias, 5)

RIZZINI, C. T. Tratado de Fitogeografia do Brasil. São Paulo: Hucitec/Edusp, 1979.

SETZER, J. Atlas climático e ecológico do Estado de São Paulo. São Paulo: Comissão Interestadual da Bacia Paraná -Uruguai e Centrais Elétricas de Estado de São Paulo, 1966.

SILVA, A. F. et al. Composição florística e grupos ecológicos das espécies de um trecho de floresta semidecídua submontana da Fazenda São Geraldo, Viçosa-MG. Revista Árvore, v.27, n.3, p.311319, 2003.

SILVA, N. R. S. et al. Composição florística e estrutura de uma floresta estacional montana em Viçosa, MG. Revista Árvore, v.28, n.3, p.397-405, 2004.

SWAINE, M. D.; WHITMORE, T. C. On the definition of ecological species groups in tropical rain forests. Vegetatio, v.75, p.81-86, 1988.

TORQUEBIAU, E. F. Mosaic patterns in dipterocarps forest in Indonesia, and their implications for practical forestry. Journal of Tropical Ecology, v.2, p.301-325, 1986.

WHITMORE, T. C. Tropical rain forest of the Ear East. Oxford: Claredon Press, 1975.

WHITMORE, T.C. An introduction to tropical rain forest. New York: Oxford University Press, 1990.

WILLS, C. et al. Nonrandom process maintain diversity in tropical forests. Science, v.311, p.527-531, 2006. 